\title{
Bazı önemli dış mekan süs bitkilerine ait yeşil çeliklerin köklenme performansları*
}

\author{
Güzella YILMAZ ${ }^{\circledR 1}$, Kenan YILDIZ $\mathbb{D} 1$ \\ ${ }^{1}$ Tokat Gaziosmanpașa Üniversitesi Ziraat Fakültesi Bahçe Bitkileri Bölümü \\ *Yüksek lisans tezinden hazırlanmıștır.
}

Alınış tarihi: 21 Nisan 2020, Kabul tarihi: 5 Ekim 2020

Sorumlu yazar: Kenan YILDIZ, e-posta: kenan.yildiz@gop.edu.tr

\section{Öz}

Erguvan (Cercis siliquastrum), manolya (Magnolia soulangeana), söğüt yapraklı ispir (Spiraea salicifolia), Japon ayvası (Chaenomeles japonica), filbahri (Philadelphus coronarius saxifragaceae), leylak (Syringa vulgaris), oya ağacı (Lagerstroemia indica) ve gülhatmiden (Alcea rosea) alınan yeșil çeliklerin köklenme performansı üzerine indol bütirik asit (IBA) uygulamasının etkisi incelenmiştir. Erguvan çeliklerine 8000 ppm diğer türlerden alınan çeliklere ise 2000 ppm IBA uygulaması yapılmıștır. Erguvan çelikleri hem kontrol (0 ppm) hem de 8000 ppm IBA uygulamasında düșük oranda (\% 6 ve $\%$ 10) bir köklenme başarısı göstermiştir. Japon ayvasında da IBA uygulamasına rağmen düșük oranda (\%33) köklenme olmuştur. 2000 ppm IBA uygulaması ile manolyada \% 100, sögüt yapraklı ispirde \% 97.7, filbahride \% 67.7, leylakta \% 73.7, oya ağacından \% 61 oranında köklenme elde edilmiştir. Gülhatmi çelikleri ise hem hormon uygulamasında hem de kontrol uygulamasindan \% 100 oranında köklenme başarısı gözlenmiştir. IBA uygulamaları manolya, japon ayvası, filbahri, leylak ve oya ağacı çeliklerinde kök sayısında önemli artışlara neden olurken, gülhatmi çeliklerinde kök sayısını azaltmıștır.

Anahtar kelimeler: Adventif kök, süs bitkileri, çelikle çoğaltma, oksin
Rooting performances of soft-wood cuttings of some important outdoor ornamental plants

\begin{abstract}
The effect of IBA application on the rooting performance of soft-wood cuttings taken from redbud (Cercis siliquastrum), magnolia (Magnolia soulangeana), spiraea (Spiraea salicifolia), Japanese quince (Chaenomeles japonica), mock-orange (Philadelphus coronarius saxifragaceae), lilac (Syringa vulgaris), crapemyrtle (Lagerstroemia indica) and hollyhock (Alcea rosea) ornamental plants were investigated. The cuttings of redbud were treated with 8000 ppm IBA, the cuttings from other species were dipped into 2000 ppm IBA before planting. Redbud cuttings showed low rooting success in both control (6\%) and 8000 ppm IBA $(10 \%)$ treatment. The Japanese quince showed a low $(33 \%)$ rooting rate, even with the application of IBA. $2000 \mathrm{ppm}$ IBA increased rooting ratios to $100 \%$, $97.7 \%, 67.7 \%, \quad 73.7 \%$ and $61 \%$ for magnolia, spiraea, mock-orange, lilac and crapemyrtle, respectively. In hollyhock cuttings, $100 \%$ rooting success was observed in both IBA and control treatments. While IBA applications caused significant increases in the number of roots in magnolia, Japanese quince, mock-orange, lilac and crapemyrtle cuttings, it decreased the number of roots in hollyhock cuttings.
\end{abstract}

Key words: Adventif root, auxin, ornamental plants, propagation by cutting 


\section{Giriş}

Kentleşmenin etkisi ile doğadan uzaklaşan insanların doğa özleminin artması ve çevre sorunlarının ortaya çıkması, süs bitkilerinin önemini artırarak büyük bir pazarın doğmasına neden olmuştur. Özellikle son 4050 yıldır süs bitkileri üretim ve pazarlamasında, çok hızlı gelişme ve değişme yaşanmaktadır. Günümüzde, bu sektör pek çok ülkede ekonomiye katkı sağlayan etkili bir sektör olarak kabul edilmektedir (Ay, 2009; Cengiz ve ark., 2017).

Süs bitkileri içinde önemli bir yer tutan dış mekan süs bitkileri genellikle park ve bahçelerin düzenlenmesinde, karayolu ve metropollerin ağaçlandırılmasında ve dinlenme (rekreasyon) sahalarında kullanılan ağaç, çalı ve otsu bitkilerden oluşmaktadır (Sağlık ve ark., 2012; Cengiz ve ark., 2017).

Türkiye dış mekan süs bitkilerinde önemli gelişmeler yaşanmasına rağmen, üretimin yeterli olmadığı bildirilmektedir. Özellikler büyük boylu fidan üretiminde sıkıntılar bulunmaktadır. İstanbul ve Ankara Büyükşehir Belediyelerince fazla miktarda boylu fidan kullanılmakta ve talep edilmektedir. $\mathrm{Bu}$ talepler bașta İtalya olmak üzere, değișik ülkelerden ithalat yolu ile karşılanmaktadır. Dış mekan süs bitkilerinde bitki standardı olmadığından fiyatlar çok değişkenlik göstermekte, fiyatlandırmada çeșitli faktörler rol oynamaktadır. Bitkinin yüksek boylu ve formunu almış olması, kalite özeliklerinden olup, fiyat oluşumunda en büyük etkendir. Genellikle yavaş büyüyen, çoğaltılması zor ve beceri isteyen özel bitkiler çok yüksek fiyatlarla satılabilmektedir. Dıș mekan süs bitkileri yetiștiriciliği için ülkemizin ekolojik koşulları çok uygun olmasına karșın, üretim tekniklerinin yetersiz, ișletmelerin sermayelerinin sınırlı oluşu ve mekanizasyonun yaygınlaştırılamaması, özellikle yüksek boylu fidan üretimini sınırlamaktadır (Anonim, 2012).

Ekonomik anlamda önemi her geçen gün artan ve yetiştiriciye önemli düzeyde gelir getiren bu sektörde arzu edilen seviyeye ulaşılmanın önemli faktörlerden bir tanesi de kaliteli fidan yetiștirmektir. Süs bitkileri, tohumla veya vejetatif çoğaltma metotlarından birisiyle çoğaltılmaktadır. Dıș mekan süs bitkileri grubuna giren ağaç ve çalılar ise yine tohumla çoğaltma yanında, büyük oranda vejetatif yollarla çoğaltılmaktadır. Vejetatif çoğaltma yöntemleri arasında ise çelikle çoğaltma sağladığı birçok avantajdan dolayı daha yaygın kullanılmaktadır. Çelikle çoğaltma, kolay ve ucuz olmasının yanında, küçük bir alanda çok sayıda bitkinin çoğaltılmasına imkan vermesi nedeni ile tercih edilmektedir. Köklü birey elde etmek için ana bitkinin gövde, dal, kök ve yapraklarından kesilerek hazırlanan parçalara çelik, bu parçalarla yapılan üretime de çelikle üretim denilmektedir. Çelikler çelik alınan bitki kısmına göre dal çeliği, kök çeliği, yaprak-göz çeliği veya göz çeliği gibi farklı isimlerle tanımlanmaktadır. Süs bitkilerinin çoğaltılmasında genel olarak bu çelik tiplerinden dal çelikleri daha çok tercih edilmektedir (Anonim, 2007).

Süs bitkileri yetiștiriciliği hem dünyada hem de ülkemizde giderek önemli bir üretim alanı olmasına rağmen, ülkemizde süs bitkileri yetiștiriciliği ve süs bitkilerinin çoğaltılması konusunda sınırlı sayıda bilimsel çalışma bulunmaktadır. Bu nedenle bu çalışmada, dış mekan süs bitkileri grubunda yer alan ve çevre düzenleme çalışmalarında daha çok tercih edilen bazı türlerin çelikle çoğaltma ve köklenme başarılarının belirlenmesi amaçlanmıştır.

\section{Materyal ve Yöntem}

$\mathrm{Bu}$ çalışma Gaziosmanpaşa Üniversitesi Ziraat Fakültesi Bahçe Bitkileri uygulama alanında bulunan çelikle çoğaltma ünitesinde yürütülmüştür. Çalışmada, Tokat'ta bulunan özel bir işletmeden temin edilen erguvan (Cercis siliquastrum), manolya (Magnolia soulangeana), sögüt yapraklı ispir (Spiraea salicifolia), Japon ayvası (Chaenomeles japonica ), filbahri (Philadelphus coronarius saxifragaceae), leylak (Syringa vulgaris), oya ağacı (Lagerstroemia indica) bitkilerine ait yeşil çelikler kullanılmıştır.

Bütün türlerde, 26 Temmuz tarihinde alınan yıllık sürgünler 10-12 cm uzunluğunda kesilerek yeşil çelik olarak kullanılmıştır. Köklenme sürecinde yapraklardan oluşacak su kaybını azaltmak için çeliklerin alt kısmındaki yapraklar koparılmış, üst kısımda ise iki üç yaprak bırakılmıştır. Manolya gibi büyük yapraklı çeliklerde ise üst kısımda bırakılan yaprakların yarısı kesilerek 2-3 adet yarım yaprak bırakılmıştır. Çelikler hazırlanırken alt kısmı gözün hemen altında düz, üst kısmı ise eğimli olarak kesilmiştir. Hazırlanan çelikler mantari hastalık bulașma riskine karșı, \% 0.2 oranında hazırlanan bir fungusitle muamele edilmiştir. Bu amaçla hazırlanan çeliklerin tamamı kısa bir süre (2-3 dakika) fungusit çözeltisine batırılmıştır. Fungusit çözeltisinden çıkarılan çelikler yaklaşık 5 dakika bekletildikten sonra, hormon uygulaması yapılmıştır. Her bir tür için toplam 90 çelik kullanılmış olup bunların yarısı kontrol olarak kullanılırken diğer yarısı IBA çözeltisine batırılmıştır. Diğerlerine göre köklenmesi 
daha zor olarak bilinen (Karam ve Gebre, 2004) erguvan çeliklerine $8000 \mathrm{ppm}$, diğer türlerin çeliklerine ise $2000 \mathrm{ppm}$ indol bütirik asit (IBA) uygulaması yapılmıştır. Hormon uygulaması, hazırlanan çeliklerin alttan yaklaşı $1 \mathrm{~cm}$ kısımlarının 5 saniye süre ile hormon çözeltisine batırılması şeklinde yapilmıştır. Hormon çözeltisinden çıkarılan çelikler, alkolün uçması için 2-3 dakika bekletildikten sonra köklendirme ortamına dikilmiștir. Köklendirme ortamı olarak perlit kullanılmıştır. Çelikler 2/3'lük kısımları perlit içinde kalacak șekilde dikilmiștir. Sisleme sistemine sahip olan köklendirme ortamında sisleme sistemi 5 dakikada 5 saniye çalışacak şekilde ayarlanmıştır. Köklendirme ortamında 2 ay bekletilen çelikler, bu sürenin sonunda köklendirme masalarından çıkarılarak, köklenme oranları, ortalama kök uzunlukları, ortalama kök çapları, çelik başına ortalama kök sayıları belirlenmiştir.

Çalışma, tam şansa deneme desenine göre üç tekerrürlü ve her tekerrürde 15 çelik olacak şekilde kurulmuştur. Elde edilen veriler önce varyans analizine tabi tutulmuş daha sonra, uygulama ortalamaları arasında önemli bir farklılığın olup olmadığı LSD çoklu karşılaştırma testi ile tespit edilmiştir.

\section{Bulgular}

Kontrol olarak kullanılan Erguvan çeliklerinin sadece \% 6'sında köklenme olmuştur. IBA uygulamasında (8000 ppm) ise \% 10'luk bir köklenme elde edilmiş olup bunun anlamlı bir artıș olmadığı belirlenmiștir. Benzer șekilde, kök çapı ve çelik bașına kök sayıları da IBA uygulamasında kontrolden yüksek görünmesine rağmen aradaki fark istatistikî olarak önemsiz bulunmuștur. Kök uzunluğu ise kontrol çeliklerine göre, IBA uygulaması çeliklerinde önemli derecede daha yüksek bulunmuştur. Kontrol çeliklerinde $5.5 \mathrm{~mm}$ olarak ölçülen ortalama kök uzunluğu 8000 ppm IBA uygulanan çeliklerde 14.6 mm olarak belirlenmiştir (Çizelge 1).

Çizelge 1. IBA uygulamasının erguvan yeşil çeliklerinde adventif kök oluşumu üzerine etkisi

\begin{tabular}{ccccc}
\hline Uygulama & Kök (\%) & $\begin{array}{c}\text { Kök } \\
\text { uzunluğu } \\
(\mathrm{mm})\end{array}$ & $\begin{array}{c}\text { Kök çapı } \\
(\mathrm{mm})\end{array}$ & $\begin{array}{c}\text { Kök sayısı } \\
\text { (adet/çelik) }\end{array}$ \\
\hline $\begin{array}{c}\text { Kontrol } \\
8000 \mathrm{ppm} \\
\text { IBA }\end{array}$ & $6.0 \mathrm{a}$ & $5.5 \mathrm{~b}$ & $1.2 \mathrm{a}$ & $2.0 \mathrm{a}$ \\
\hline $\mathrm{LSD}_{0.05}$ & $4.0 \mathrm{a}$ & $14.6 \mathrm{a}$ & $3.6 \mathrm{a}$ & $6.0 \mathrm{a}$ \\
\hline
\end{tabular}

Aynı sütun aynı harfle gösterilen uygulama ortalamaları arasındaki fark 0.05 ihtimal seviyesinde önemli değildir.
Manolyada kontrol çeliklerinde \% 73.3 olan köklenme 2000 ppm IBA uygulaması ile önemli bir artış göstermiş ve \% 100'e ulaşmıştır. IBA çelik başına kök sayısında belirgin bir artışa neden olmuştur. Kontrolde çelik başına ortalama 8.3 adet kök oluşurken, IBA çözeltisine batırllan çeliklerde bu sayı 77.9 olarak belirlenmiştir. Kök uzunluğu ve kök çapı açısından IBA uygulamasından kaynaklanan önemli bir değişim tespit edilememiştir. (Çizelge 2).

Cizelge 2. IBA uygulamasının manolya yeșil çeliklerinde adventif kök oluşumu üzerine etkisi

\begin{tabular}{ccccc}
\hline Uygulama & Kök (\%) & $\begin{array}{c}\text { Kök } \\
\text { uzunluğu } \\
(\mathrm{mm})\end{array}$ & $\begin{array}{c}\text { Kök çapı } \\
(\mathrm{mm})\end{array}$ & $\begin{array}{c}\text { Kök sayısı } \\
\text { (adet/çelik) }\end{array}$ \\
\hline $\begin{array}{c}\text { Kontrol } \\
\text { 2000 ppm } \\
\text { IBA }\end{array}$ & $73.3 \mathrm{~b}$ & $58.8 \mathrm{a}$ & $2.0 \mathrm{a}$ & $8.3 \mathrm{~b}$ \\
\hline LSD $_{0.05}$ & $100.0 \mathrm{a}$ & $61.1 \mathrm{a}$ & $1.7 \mathrm{a}$ & $77.9 \mathrm{a}$ \\
\hline
\end{tabular}

Aynı sütun aynı harfle gösterilen uygulama ortalamaları arasındaki fark 0.05 ihtimal seviyesinde önemli değildir.

Hormon uygulanmadan dikilen sögüt yapraklı ispir yeşil çeliklerinin \% 79.0'unun köklendiği tespit edilmiştir. IBA uygulandıktan sonra dikilen çeliklerde ise \% 97.7 oranında bir köklenme oluşmasına rağmen bu fark istatistiki olarak önemsiz bulunmuştur. IBA uygulaması kök çapı ve çelik başına kök sayılarında da önemli bir değişime neden olmamıștır. $\mathrm{Bu}$ türde tek önemli farklılık kök uzunluğunda gözlenmiş olup IBA uygulamasının kök uzunluğunda azalmaya neden olduğu belirlenmiștir (Çizelge 3).

Çizelge 3. IBA uygulamasının söğüt yapraklı ispir çeliklerinde adventif kök oluşumu üzerine etkisi

\begin{tabular}{ccccc}
\hline Uygulama & Kök (\%) & $\begin{array}{c}\text { Kök } \\
\text { uzunluğu } \\
(\mathrm{mm})\end{array}$ & $\begin{array}{c}\text { Kök çapı } \\
(\mathrm{mm})\end{array}$ & $\begin{array}{c}\text { Kök sayısı } \\
\text { (adet/çelik) }\end{array}$ \\
\hline $\begin{array}{c}\text { Kontrol } \\
2000\end{array}$ & $79.0 \mathrm{a}$ & $186.6 \mathrm{a}$ & $1.6 \mathrm{a}$ & $20.0 \mathrm{a}$ \\
$\begin{array}{c}\text { ppm IBA } \\
\text { LSD }_{0.05}\end{array}$ & $97.7 \mathrm{a}$ & $107.2 \mathrm{~b}$ & $1.7 \mathrm{a}$ & $18.4 \mathrm{a}$ \\
\hline
\end{tabular}

Aynı sütun aynı harfle gösterilen uygulama ortalamaları arasındaki fark 0.05 ihtimal seviyesinde önemli değildir.

Japon ayvası kontrol çeliklerinde \% 30, 2000 ppm IBA uygulanan çeliklerde ise \% 33.3 oranında köklenme olmuştur. Ortalama kök uzunluğu, kontrol çeliklerinde $25.5 \mathrm{~mm}$, IBA uygulanan çeliklerde ise $50.9 \mathrm{~mm}$ bulunmuş olmasına rağmen aradaki fark 
istatistiksek olarak önemli bulunmamıştır. Ortalama kök çapı kontrol uygulamasına göre IBA uygulamasında daha düşük olarak belirlenmiștir. Çelik başına ortalama kök sayısı ise IBA uygulamasına bağlı olarak önemli derecede artış göstermiştir. Kontrol çeliklerinde çelik başına ortalama kök sayısı 4.7 iken, bu değer IBA uygulanan çeliklerde 8.2 olarak tespit edilmiştir (Çizelge 4).

Çizelge 4. IBA uygulamasının Japon ayvası yeşil çeliklerinde adventif kök oluşumu üzerine etkisi

\begin{tabular}{ccccc}
\hline Uygulama & Kök (\%) & $\begin{array}{c}\text { Kök } \\
\text { uzunluğu } \\
(\mathrm{mm})\end{array}$ & $\begin{array}{c}\text { Kök çapı } \\
(\mathrm{mm})\end{array}$ & $\begin{array}{c}\text { Kök sayıs } \\
\text { (adet/çelik) }\end{array}$ \\
\hline $\begin{array}{c}\text { Kontrol } \\
2000\end{array}$ & $30.0 \mathrm{a}$ & $25.5 \mathrm{a}$ & $1.5 \mathrm{a}$ & $4.7 \mathrm{~b}$ \\
ppm IBA & $33.3 \mathrm{a}$ & $50.9 \mathrm{a}$ & $1.0 \mathrm{~b}$ & $8.2 \mathrm{a}$ \\
\hline LSD $_{0.05}$ & 10.4 & 33.3 & 0.1 & 1.2 \\
\hline
\end{tabular}

Aynı sütun aynı harfle gösterilen uygulama ortalamaları arasındaki fark 0.05 ihtimal seviyesinde önemli değildir.

Filbahri çeliklerinde 2000 ppm uygulamasında kontrol uygulamasından bir miktar daha yüksek köklenme elde edilmesine karşın aradaki farkın önemli olmadığı belirlenmiştir. Kök uzunluğu açısından da IBA uygulamasının önemli bir etkisi tespit edilememiştir. Yapılan IBA uygulaması kök çapında ve kök sayısında önemli bir artışa neden olmuştur. Özellikle kök sayısında IBA'dan kaynaklanan artış oldukça belirgin olup, kontrol uygulamalarında çelik başına ortalama 5.3 adet kök oluşurken, 2000 ppm IBA uygulaması ile bu sayı 58.6 adet olarak belirlenmiştir (Çizelge 5).

Çizelge 5. IBA uygulamasının filbahri yeşil çeliklerinde adventif kök oluşumu üzerine etkisi

\begin{tabular}{ccccc}
\hline Uygulama & Kök (\%) & $\begin{array}{c}\text { Kök } \\
\text { uzunluğu } \\
(\mathrm{mm})\end{array}$ & $\begin{array}{c}\text { Kök çapı } \\
(\mathrm{mm})\end{array}$ & $\begin{array}{c}\text { Kök sayısı } \\
\text { (adet/çelik) }\end{array}$ \\
\hline $\begin{array}{c}\text { Kontrol } \\
2000\end{array}$ & $53.3 \mathrm{a}$ & $39.3 \mathrm{a}$ & $0.4 \mathrm{~b}$ & $5.3 \mathrm{~b}$ \\
ppm IBA & $67.7 \mathrm{a}$ & $41.9 \mathrm{a}$ & $0.8 \mathrm{a}$ & $58.6 \mathrm{a}$ \\
\hline $\mathrm{LSD}_{0.05}$ & 14.9 & 6.2 & 0.1 & 2.9 \\
\hline
\end{tabular}

Aynı sütun aynı harfle gösterilen uygulama ortalamaları arasındaki fark 0.05 ihtimal seviyesinde önemli değildir.

Hormon uygulaması yapılmayan leylak çeliklerinin $\%$ 80'i kök oluştururken IBA uygulanan çeliklerde bu oran \% 73.7 olarak belirlenmiş ve aradaki fark önemsiz bulunmuştur. Kök çapı açısından da kontrol ile IBA uygulaması arasında önemli bir fark ortaya çıkmamıştır. Kök uzunluğu ve çelik başına kök sayısında ise kontrole kıyasla IBA uygulamasından kaynaklanan önemli artışların olduğu bulunmuştur. Kontrolde $45.8 \mathrm{~mm}$ olan ortalama kök uzunluğu IBA uygulamasında $60.0 \mathrm{~mm}$ olarak ölçülmüştür. Çelik başına kök sayısı ise kontrolde 2.9 iken IBA uygulanan çeliklerde 19.3 olarak tespit edilmiştir (Çizelge 6).

Çizelge 6. IBA uygulamasının leylak yeşil çeliklerinde adventif kök oluşumu üzerine etkisi

\begin{tabular}{lcccc}
\hline Uygulama & Kök (\%) & $\begin{array}{c}\text { Kök } \\
\text { uzunluğu } \\
(\mathrm{mm})\end{array}$ & $\begin{array}{c}\text { Kök çapı } \\
(\mathrm{mm})\end{array}$ & $\begin{array}{c}\text { Kök sayısı } \\
\text { (adet/çelik) }\end{array}$ \\
\hline $\begin{array}{c}\text { Kontrol } \\
2000 \\
\text { ppm IBA }\end{array}$ & $\begin{array}{l}73.7 \mathrm{a} \\
\mathrm{LSD}\end{array}$ & $60.0 \mathrm{a}$ & $0.8 \mathrm{a}$ & $19.3 \mathrm{a}$ \\
\hline $\begin{array}{l}\text { Aynı sütun } \\
\text { arasındaki fark 0.05 ihtimal seviyesinde önemli değildir. }\end{array}$
\end{tabular}

Oya ağacı bitkisinde kontrol çeliklerinin \% 54.0'ı IBA uygulanan çeliklerin ise \% 61.0'ı adventif kök oluşturmuş olup aradaki fark önemli bulunmamıştır. Bu bitkinin yeşil çeliklerine dikim öncesi uygulanan IBA'nın ortalama kök uzunluğunu artırdığ belirlenmiştir. Kontrol çeliklerinde $54.5 \mathrm{~mm}$ olan ortalama kök uzunluğu, IBA uygulanan çeliklerde $66.5 \mathrm{~mm}$ olarak ölçülmüştür. IBA çelik başına ortalama kök sayısında da önemli seviyede bir artışa neden olmuştur. Kontrol uygulamasında 6.3 olan çelik başına ortalama kök sayısı, IBA uygulamasında 13.7 olarak belirlenmiştir. Kök çapı ise tam tersine IBA uygulanan çeliklerde daha düşük bulunmuştur (Çizelge 7).

Çizelge 7. IBA uygulamasının oya ağacı yeşil çeliklerinde adventif kök oluşumu üzerine etkisi

\begin{tabular}{ccccc}
\hline Uygulama & Kök (\%) & $\begin{array}{c}\text { Kök } \\
\text { uzunluğu } \\
(\mathrm{mm})\end{array}$ & $\begin{array}{c}\text { Kök çapı } \\
(\mathrm{mm})\end{array}$ & $\begin{array}{c}\text { Kök sayısı } \\
\text { (adet/çelik) }\end{array}$ \\
\hline $\begin{array}{c}\text { Kontrol } \\
2000\end{array}$ & $54.0 \mathrm{a}$ & $54.5 \mathrm{~b}$ & $1.9 \mathrm{a}$ & $6.3 \mathrm{~b}$ \\
$\mathrm{ppm} \mathrm{IBA}$ & $61.0 \mathrm{a}$ & $66.5 \mathrm{a}$ & $1.6 \mathrm{~b}$ & $13.7 \mathrm{a}$ \\
\hline LSD $_{0.05}$ & 12.9 & 5.9 & 0.2 & 3.3 \\
\hline
\end{tabular}

Aynı sütun aynı harfle gösterilen uygulama ortalamaları arasındaki fark 0.05 ihtimal seviyesinde önemli değildir.

Gülhatmi bitkisinde, hem hormon uygulanan hem de hiçbir uygulama yapılamayan kontrol çeliklerinin tamamı adventif kök oluşturmuştur. Köklenme oranı yanında kök kalitesini belirleyen kök uzunluğu ve ortalama kök sayıları da yüksek bulunmuştur. 
Ortalama kök uzunluğu kontrol çeliklerinde 102.3 mm olarak ölçülmüştür. $\mathrm{Bu}$ değer IBA uygulananlarda daha düşük olarak tespit edilmekle birlikte aradaki fark istatistiksel olarak önemsiz bulunmuştur. Kök çapı açısından kontrol ile IBA uygulaması arasında önemli bir farklılık ortaya çıkmamıştır. Kontrole kıyasla IBA' nın çelik başına kök sayısında önemli bir azalmaya neden olduğu görülmüştür. Kontrol çeliklerinde 80.4 olan çelik başına ortalama kök sayısı, IBA uygulanan çeliklerde 30.3 olarak belirlenmiştir (Çizelge 4.8).

Çizelge 8. IBA uygulanmış gülhatmi bitkisi yeşil çeliklerinin köklenme durumu

\begin{tabular}{|c|c|c|c|c|}
\hline Uygulama & Kök (\%) & $\begin{array}{c}\text { Kök } \\
\text { uzunluğu } \\
(\mathrm{mm})\end{array}$ & $\begin{array}{l}\text { Kök çapı } \\
\text { (mm) }\end{array}$ & $\begin{array}{c}\text { Kök sayısı } \\
\text { (adet/çelik) }\end{array}$ \\
\hline Kontrol & 100 & $102.3 \mathrm{a}$ & $0.7 \mathrm{a}$ & $80.4 \mathrm{a}$ \\
\hline $\begin{array}{c}2000 \\
\text { ppm IBA }\end{array}$ & 100 & 87.7 a & $1.3 \mathrm{a}$ & $30.3 \mathrm{~b}$ \\
\hline $\mathrm{LSD}_{0.05}$ & 0 & 22.4 & 0.8 & 4.1 \\
\hline
\end{tabular}

\section{Tartışma}

İncelenen süs bitkileri içerisinde en düşük köklenme erguvan bitkisinde gözlenmiştir. Bu bitkide kontrol çelikleri \% 6, 8000 ppm IBA uygulanan çeliklerde ise $\% 10$ oranında bir köklenme elde edilmiştir. Erguvan çeliklerinde köklenmenin kolay olmadığı Karam ve Gebre (2004) tarafından da bildirilmiştir. $\mathrm{Bu}$ araştırıcılar erguvanda köklenme yüzdesinin, çeliğin sürgün üzerindeki pozisyonuna ve çelik alma zamanına bağlı olarak büyük bir varyasyon gösterdiğini belirterek; ilkbahar ve kış döneminde alınan çeliklerde oksin uygulamasına rağmen, köklenme elde edemediklerini vurgulamışlarıdır. Aynı araştırıcılar yaz mevsiminde alınan sürgün ucu çeliklerinde \% 43, dip çeliklerde ise \% 13 oranında bir köklenme elde ettiklerini ifade etmişlerdir. $\mathrm{Bu}$ çalışmamızda yıllık sürgünün tamamı çelik hazırlamada kullanılmış olup, sürgünün uç ve dip kısmı ayrı ayrı değerlendirilmemiştir. Nispeten düşük köklenme elde edilmesinin nedeni uç çeliklerin az olmasından kaynaklanmış olabilir. Karam ve Gebre (2004) oksin uygulamasının erguvan çeliklerinde kök uzunluğu, kuru kök ağılığı ve kök sayısını artırdığını kaydetmiştir. Bu çalışmada da benzer şekilde kök uzunluğu IBA uygulaması ile önemli derecede artmıştır. Çelik başına kök sayısında da IBA uygulaması ile bir miktar artış gözlenmiş ancak bu artış istatistikî olarak önemli bulunmamiștır.
Manolya çeliklerinde 2000 ppm IBA uygulaması ile \% 100 oranından köklenme elde edilmiştir. Benzer sonuçlar farklı zamanlarda çelik alarak IBA uygulamasının etkisini inceleyen Martin ve Ingram (1989) tarafında da bildirilmiştir. Aynı araştırıcılar, bu çalışmadan elde edilen bulgularla uyumlu olarak, IBA uygulamasının kök sayısı ve kök uzunluğunu artırdığını belirlemişlerdir.

Söğüt yapraklı ispir (Spiraea salicifolia) çeliklerinde de yüksek oranda bir köklenme elde edilmiștir. IBA uygulanan çeliklerdeki köklenme oranı kontrol çeliklerinden daha yüksek bulunmasına karşın tekerrürüler arasında büyük bir varyasyon olmasında dolayı aradaki fark önemli bulunmamıştır. Diğer bitkilerin aksine, bu bitkide uygulanan IBA, ortalama kök uzunluğunda önemli bir azalmaya neden olmuştur. Bu durum, hormonsuz da köklenme yeteneği yüksek olan bu tür için, 2000 ppm IBA dozunun yüksek gelmesi ve engelleyici etki göstermesinden kaynaklanmış olabilir. Nitekim (Ion, 2011) da söğüt yapraklı ispir çelikleri ile yaptığı denemelerinde başarılı sonuçlar aldığını; farklı dönemlerde aldığı yeşil çeliklerde hormon uygulaması yapmadan \% 58 ile \% 78 arasında; odun çeliklerinde ise \% 81 ile \% 93 arasında köklenme elde ettiğini bildirmiştir.

Japon ayvasının çelikle çoğaltılması konusunda yapılan çalışmalarda, farklı sonuçlar rapor edilmiştir. Bazı araştırıcılar Japon ayvasının odun çelikleri ile çoğaltılmasının zor olduğunu (Albrecht ve Schulze, 1980; Ratomskyte, 1990; Wells, 1961), buna karşıllk yeşil çelikle çoğaltılabileceği bildirmişledir (Kviklys, 1996; 1998; Kviklys ve Rumpunen, 1996). Kauppinen ve ark. (2003) ise odun çeliklerinde köklenme oranının yıllara göre önemli değişiklik gösterdiğini, birinci yll $100 \mathrm{mg} / \mathrm{I}$ IBA uygulanan çeliklerde \% 85, ikinci yll ise \% 21 oranında köklenme elde ettiğini bildirmişlerdir. Yeşil çeliklerle yapılan bir çalışmada ise, çelikler 18 saat süreyle 10 veya $30 \mathrm{mg} / \mathrm{I}$ IBA çözeltisine batırılmış ve köklenme oranının, çeliğin sürgün üzerindeki pozisyonuna göre değiştiği bildirilmiştir. Sürgünün dip, orta ve uç kısmından alınan çeliklerde sırasıyla \%37, \%45 ve \%70 oranında köklenme elde edilmiştir. Aynı çalışmada köklenme oranının çelik uzunluğuna bağlı olarak önemli farklılık gösterdiği, uzun çeliklerin daha iyi köklendiği saptanmıștır. Ayrıca sürgünün dip ve uç kısmından alınan çelikler karşılaştırılmış ve dip kısımda alınan çeliklerde köklenme oranının 
biraz daha yüksek olduğu bildirilmiştir. Bu çalışmada ise kontrol çeliklerinden $\% 30$ oranında bir köklenme elde edilirken, \% 33 köklenme elde edilen 2000 ppm IBA uygulamasının önemli bir etkisi ortaya çıkmamıştır. Bu şekilde farklı literatür sonuçları Japon ayvasında, hormon uygulaması yanında köklenme başarısını etkileyen birçok faktörün olduğunu ortaya koymaktadır.

Çalıșmada ele alınan diğer bir süs bitkisi filbahrinin (Philadelphus coronarius saxifragaceae) çelikle çoğaltılması konusunda literatürde fazla bilgi bulunmamakla birlikte, Philadelphus türlerinin odun çeliği ve yeşil çelikle çoğaltılabileceği bildirilmiştir (Hartmann ve ark., 1990; Macdonald, 1986; Sutton ve Johnson, 1974; Dirr ve Heuser, 1987; Marchant ve Sherlock, 1984). Bu çalışmada, hormonsuz çeliklerin $\%$ 53.3, IBA uygulananların ise \% 66.7 oranından köklendikleri tespit edilmiştir. Bu sonuç filbahri bitkisinin çelikle çoğalma potansiyelinin olduğunu göstermektedir. Farklı konsantrasyonlarda hormon uygulaması ile daha yüksek başarı oranları elde edilebilir. En uygun hormon konsantrasyonunu belirlemeye yönelik çalışmalar faydalı olacaktır.

Leylak bitkisinin zor köklenen bir tür olduğu bildirilmekle beraber, sürgün gelişiminin hızlı olduğu yaz mevsiminin ilk günlerinde alınan çeliklerle çoğaltılabileceği bildirilmiștir (Howard,1996). Ford ve ark. (2002), mayis ortasından temmuz başına kadar bir hafta arayla alınan ve IBA uygulanan yeşil çeliklerde köklenme oranının, çelik alma tarihine bağlı olarak, \% 94 ile \% 4 arasında değişim gösterdiği kaydetmişlerdir. Dinlenme döneminde alınan çeliklerde ise hemen hemen hiç köklenmenin olmadığını bildirmişlerdir Bu çalışmada ise kontrol çeliklerinde $\% 80$ oranında bir köklenme elde edilirken, köklenmeyi teşvik edici bir hormon olan IBA uygulamasının köklenme oranı üzerine önemli bir etkisinin olmadığ $\breve{g}$ tespit edilmiştir. Diğer taraftan IBA'nın kök uzunluğu ve çelik başına kök sayısında önemli artışlara neden olduğu görülmüştür. Leylak bitkisinin çelikle çoğaltılması konusunda çalışan Cameron ve ark. (2003), çelik alma zamanına bağlı olarak bu türde köklenme oranının önemli derecede değiştiğini, yaz mevsiminin ilk günlerinde alınan çeliklerde bașarının daha yüksek olduğunu, sonbahara doğru köklenme oranının azaldığını belirtmişleridir. Aynı araştırıcılar dinlenme döneminde yapılan sert budamanın sürgün gelișimini hızlandırdığını ve bu sürgünlerden alınan çeliklerin daha iyi köklendiğini kaydetmişlerdir. Howard ve Ridout (1992) çelik alınan ana bitkinin iki haftadan fazla süreyle karanlıkta tutulmasının köklenme oranını artırdığını bildirmişlerdir.

Oya ağacında da tatminkâr bir köklenme oranı elde edilmiş olup, kontrol çeliklerinde $\% \quad 54$ olan köklenme oranı, 2000 ppm IBA uygulaması ile \% 61'e yükselmiștir. Ancak IBA'dan kaynaklanan bu artıș istatistiksel olarak önemli bulunmamıștır. Köklenme üzerine IBA'nın etkisi kök uzunluğu ve çelik başına kök sayısında daha belirgin olarak ortaya çıkmıştır. Bu çalışmada çelik alma zamanı olarak tek bir dönem ve tek IBA dozu kullanılmıştır. Farklı zamanlarda alınan çeliklerle ve farklı konsantrasyonda hormon uygulaması yapılacak bir denemede daha yüksek oranda köklenme elde edilebilir. Nitekim Hansen ve Kristiansen (2000), bazı süs bitkileri ile yaptığı çalışmalarında çelik alma zamanının köklenmede önemli etkisinin olduğunu belirtmiștir.

Gülhatmi süs çalısının herhangi bir köklenme hormonu uygulamaksızın yeșil çelikle, sisleme sistemi altında perlit ortamında başarılı bir șekilde çoğaltılabileceği görülmüştür. $\mathrm{Bu}$ bitkide hem kontrol hem de, 2000 ppm IBA uygulaması yapılan çeliklerin tamamı köklenmiştir. Köklenme oranı yanında köklenen çeliklerde kök kalitesinin de oldukça yüksek olduğu, ortalama kök uzunluğunun kontrol çeliklerinde 102.3 mm'ye ulaştığı belirlenmiştir. Bu bitkide uygulanan IBA çelik başına ortalama kök sayısında azalmaya neden olmuștur. Bu durum, hormon uygulaması olmadan da yüksek bir köklenme yeteneğine sahip olan bu türde uygulanan hormon dozunun engelleyici olabileceğini akla getirmektedir.

Sonuç olarak, bu çalışmada kullanılan 8 farklı dış mekan süs bitkisinden erguvan ve Japon ayvası hariç diğerlerinde yüksek oranlarda köklenme başarısı elde edilmiş olup, bu türlerin yeşil çelikle sisleme sistemi altında başarı ile çoğaltılabileceği belirlenmiştir. Erguvan ve Japon ayvasında ise düşük oranda da olsa bir köklenme elde edilmiştir. Bu durum bu bitkilerin yeşil çeliklerinde de köklenme potansiyelinin olduğunu ortaya koymaktadır. Bundan sonra yapılacak başka çalışmalarda, farklı uygulamalar kullanılarak bu türlerde daha yüksek oranda köklenme yüzdesi elde edilebilir. 


\section{Kaynaklar}

Albrecht, H.J., \& Schulze, G. (1980). Vermehrungvon ziergeholzendurch steckholz in plastfolienzelten. Gartenbau, 27, 122-124.

Anonim. (2007). Mesleki Eğitim ve Öğretim Sisteminin Güçlendirilmesi Projesi (MEGEP), Bahçecilik, Dış Mekân Bitkileri, Ankara 35 s.

Anonim. (2012). Sekizinci Beş Yıllık Kalkınma Planı: Bitkisel Üretim Özel İhtisas Komisyonu Süs Bitkileri Alt Komisyon Raporu. Ankara: DPT, 2001. (DPT. 2645 - ÖİK. 653) ISBN 975-19-2909-1.

Ay, S. (2009). Süs bitkileri ihracatı, sorunları ve çözüm önerileri: Yalova ölçeğinde bir araştırma. Suleyman Demirel University Journal of Faculty of Economics \& Administrative Sciences, 14(3), 423-443.

Cameron, R., Harrison-Murray, R., Fordham, M., Judd, H., Ford, Y., Marks, T., \& Edmondson, R. (2003). Rooting cuttings of Syringa vulgaris cv. Charles Joly and Corylus avellana cv. Aurea: the influence of stock plant pruning and shoot growth. Trees, 17(5), 451-462.

Cengiz, B., Dağlı, P. K., \& Yiğittekin, S. (2017). Peyzaj ekonomisi açısından peyzaj ve süs bitkileri fidanlık işletmelerine yönelik sektörel bir analiz. Bartın Orman Fakültesi Dergisi, 19(2), 50-62.

Dirr, M. A. \& Heuser C. H. W. (1987). The reference manual of woody plant propagation, Athens, GA: Varsity Press. p. 239.

Ford, Y. Y., Bonham, E. C., Cameron, R. W. F., Blake, P. S., Judd, H. L., \& Harrison-Murray, R. S. (2002). Adventitious rooting: examining the role of auxin in an easy-and a difficult-to-root plant. Plant Growth Regulation, 36(2), 149-159.

Hansen, J., \& Kristiansen, K. (2000). Root formation, bud growth and survival of ornamental shrubs propagated by cuttings on different planting dates. The Journal of Horticultural Science and Biotechnology, 75(5), 568-574.

Kester, D. E., Davies, F. T., \& Hartmann, H. T. (1990). Plant propagation: principles and practices. $5^{\text {th }} \mathrm{ed}$. Englewood Cliffs, NJ: Prentice-Hall. 657 pp.

Howard, Y. H. (1996). Relationships between shoot growth and rooting of cuttings in three contrasting species of ornamental shrub.Journal of Horticultural Science, 71(4), 591-605.

Howard, B. H., \& Ridout, M. S. (1992). A mechanism to explain increased rooting in leafy cuttings of Syringa vulgaris 'Madame Lemoine' following dark- treatment of the stockplant. Journal of Horticultural Science, 67(1), 103-114.

Ion, S. T. A. N. (2011). Propagation of some ornamental species (Ligustrum ovalifolium Hassk., Spiraea salicifolia L., Forsythia sp.) at the Botanical Garden" Al. Buia" from Craiova. Annals of the University of Craiova-Agriculture, Montanology, Cadastre Series, 41(2), 237-242.

Karam, N. S., \& Gebre, G. H. (2004). Rooting of Cercis siliquastrum cuttings influenced by cutting position on the branch and indole-butyric acid. The Journal of Horticultural Science and Biotechnology, 79(5), 792-796.

Kauppinen, S., Kviklys, D., Rumpunen, K., Stanys, V., \& Svensson, M. (2003). Propagation of Japanese quince (Chaenomeles japonica) plants. Department of Crop Science, Swedish University of Agricultural Sciences. ISBN:91-631-3765-8, s:81-98.

Kviklys, D. (1996). Genotype impact on propagation of Chaenomeles spp. by softwood cuttings. Problems of fruit plant breeding. Jelgava, Lithuania, 2, 135139.

Kviklys, D. (1998). Investigation of quantitative characters and their inheritance within dwarf quince. Summary of doctoral dissertation, Lithuanian Institute of Horticulture, Babtai, 28-39.

Kviklys, D., \& Rumpunen, K. (1996). Preliminary investigations on propagation of Chaenomeles spp. by softwood cuttings. VerksamhetsberaettelseBalsgaard, Avdelningen foer Hortikulturell Vaextfoeraedling Swedish University of Agricultural Sciences, 183-186.

Macdonald, B. (1986). Practical woody plant propagation for nursery growers, volume I. Timber Press, p. 669.

Marchant, C., \& Sherlock, J. (1984). A guide to selection and propagation of some native woody species for land rehabilitation in British Columbia.For. Res. Rep. RR84007-HQ. Victoria, BC: British Columbia Ministry of Forests, $p 117$.

Martin, C. A., \& Ingram, D. L. (1989). Rooting response of Magnolia grandiflora «Glen St. Mary» as a function of cutting harvest date and exogenously-applied hormones. Proceedings of the International Plant Propagator's Society, 39, 361-367.

Ratomskyte, G. (1990). Svarainis (Chaenomeles). Retesnieji sodo augalai. Vilnius 41-47.

Sağlık, A., Erduran, F., \& Sağlık, E. (2012). Bitkisel Tasarımın Karayolu Trafik Güvenliğinde Önemi: 
Çanakkale Örneği. 3. Karayolu Trafik Güvenliği Sетровуити, 16-18.

Sutton, R., \& Johnson, CW., 1974. Land scape plants from Utah's mountains. EC-368. Logan: Utah State University. p. 137.
Wells, J. S. (1961). Chaenomeles. In Combined Proceedings. The International Plant Propagators Society, 11, 119-123. 